\title{
Erratum zu: Mutschmann/Stimmelmayr Taschenbuch der Wasserversorgung
}

Andreas Baur, Peter Fritsch, Winfried Hoch, Gerhard Merkl, Joachim Rautenberg, Matthias Weiß und Burkhard Wricke

\section{Erratum zu: \\ A. Baur et al., Mutschmann/Stimmelmayr Taschenbuch der Wasserversorgung, https://doi.org/10.1007/978-3-658-23222-1}

Kapitel 9 wurde versehentlich mit falschem Kapiteltitel gesetzt, der Titel ist nun korrigiert von „Prozessüberwachung und -steuerung“ zu „Löschwasserversorgung“.

In Kapitel 3, Abschnitt 3.5.1, Beispiel 2 wurde „4,91 $\cdot 10^{4} \mathrm{~m}^{2}$ “ $\mathrm{zu},, 4,91 \cdot 10^{-4} \mathrm{~m}^{2}$ “ und ,0,0098 $\mathrm{m}^{3} / \mathrm{s}$ “ $\mathrm{zu}, 0,0097 \mathrm{~m}^{3} / \mathrm{s}$ “ korrigiert.

In Kapitel 3, Abschnitt 3.5.2 wurde im Beispiel im Nenner des ersten Bruches „, $\delta$ “ zu „, $\rho^{\text {“ }}$ und im Zähler des zweiten Bruches ,,2 $2 \cdot 2 \cdot 10^{5}$ “ $\mathrm{zu}, 2 \cdot 5 \cdot 10^{5}$ “ korrigiert. 